\title{
Surgical Wound Care
}

\author{
Thamilselvam $\mathbf{P}^{1 *}$, Vinothkumar $\mathbf{R}^{2}$ and Sarmukh Singh ${ }^{3}$ \\ ${ }^{1}$ Department of Surgery, National defence University of Malaysia, Malaysia \\ ${ }^{2}$ Senior Resident, AIIMS, India \\ ${ }^{3}$ Department of Surgery, HUSM, Malaysia
}

Submission: June 02, 2017; Published: June 15, 2017

*Corresponding author: Thamilselvam P, Department of Surgery, National defence University of Malaysia, Malaysia, Tel: 60177970768;

Email: thamil22@hotmail.com

\section{Introduction}

In general, the surgical wound care is very important as the management of surgical wound is concerned. The management of post-operative wounds is important to prevent potential complications such as surgical site infections and wound dehiscence from developing. So, general practitioners and the nurses for wound care, who are important part in the sub-acute management of post-operative wounds, should appreciate the physiology of wound healing and the principles of post-operative wound care [1].

Palliative wound care is complex, dynamic, and constantly evolving to balance the individual care needs of the palliative patient and his/her circle of care [2]. The patient's circle of care includes the members of the patient unit including family, significant others, caregivers, and other healthcare professionals who may be external to the current inter professional team [3]. When following a palliative wound care pathway, the focus shifts from traditional wound care, where healing and wound closure are the goals, to promoting comfort and dignity, relieving suffering, and improving quality of life [4]. Palliative care principles are adopted to meet the whole person care needs of terminally ill patients, as well as older and frailer people who often present with chronic debilitating diseases, advanced diseases associated with major organ failure (renal, hepatic, pulmonary, or cardiac), profound dementia, [5] complex psychosocial issues, diminished self-care abilities, and challenging wound-related symptoms, whether the wound has the potential to heal or not. The authors propose a paradigm that could be integrated along the continuum of wound care, and its relevance may vary with the individual's goals, disease processes, and wound condition.

\section{Aim}

The aim of this article is to update general practitioners and wound care nurses on the important aspects of surgical wound care since they have to have basic knowledge about the surgical wound care.This includes a review of the physiology behind wound healing, an update on wound cleansing and dressing methods, as well as a guide on how common surgical wound complications also should be managed.

\section{Discussion}

The main elements of surgical wound care include timely review of the wound, appropriate cleansing and dressing, as well as early recognition and active treatment of wound complications. Appropriate post-operative surgical wound care is essential in preventing potential complications, such as surgical-site infections (SSIs), wound dehiscence and haematomas. General practitioners play a major part in managing patient's postoperative wounds and it is important to appreciate the principles of post-operative wound management to minimise the incidence of wound complications.

\section{Phases of Wound Healing}

Wound healing is a dynamic process consisting of four continuous, overlapping, and precisely programmed phases. The events of each phase must happen in a precise and regulated manner. Interruptions, aberrancies, or prolongation in the process can lead to delayed wound healing or a non-healing chronic wound.

In adult humans, optimal wound healing involves the following the events:
A. Rapid hemostasis
B. Appropriate inflammation
C. Mesenchymal cell differentiation, proliferation, and migration to the wound site

D. Suitable angiogenesis

E. Prompt re-epithelialization (re-growth of epithelial tissue over the wound surface) and

F. Proper synthesis, cross-linking, and alignment of collagen to provide strength to the healing tissue. 
The first phase of hemostasis begins immediately after wounding, with vascular constriction and fibrin clot formation. The clot and surrounding wound tissue release proinflammatory cytokines and growth factors such as transforming growth factor (TGF)- $\beta$, platelet-derived growth factor (PDGF), fibroblast growth factor (FGF), and epidermal growth factor (EGF). Once bleeding is controlled, inflammatory cells migrate into the wound (chemotaxis) and promote the inflammatory phase, which is characterized by the sequential infiltration of neutrophils, macrophages, and lymphocytes. A critical function of neutrophils is the clearance of invading microbes and cellular debris in the wound area, although these cells also produce substances such as proteases and reactive oxygen species (ROS), which cause some additional bystander damage.

Macrophages play multiple roles in wound healing. In the early wound, macrophages release cytokines that promote the inflammatory response by recruiting and activating additional leukocytes. Macrophages are also responsible for inducing and clearing apoptotic cells (including neutrophils), thus paving the way for the resolution of inflammation. As macrophages clear these apoptotic cells, they undergo a phenotypic transition to a reparative state that stimulates keratinocytes, fibroblasts, and angiogenesis to promote tissue regeneration. In this way, macrophages promote the transition to the proliferative phase of healing.

T-lymphocytes migrate into wounds following the inflammatory cells and macrophages, and peak during the lateproliferative/early-remodeling phase. The role of T-lymphocytes is not completely understood and is a current area of intensive investigation. Several studies suggest that delayed T-cell infiltration along with decreased T-cell concentration in the wound site is associated with impaired wound healing, while others have reported that CD 4+ cells (T-helper cells) have a positive role in wound healing and CD8+ cells (T-suppressorcytotoxic cells) play an inhibitory role in wound healing. Interestingly, recent studies in mice deficient in both T- and B-cells have shown that scar formation is diminished in the absence of lymphocytes. In addition, skin gamma-delta T-cells regulate many aspects of wound healing, including maintaining tissue integrity, defending against pathogens, and regulating inflammation. These cells are also called dendritic epidermal T-cells (DETC), due to their unique dendritic morphology. DETC are activated by stressed, damaged, or transformed keratinocytes and produce fibroblast growth factor 7 (FGF-7), keratinocyte growth factors, and insulin-like growth factor-1, to support keratinocyte proliferation and cell survival. DETC also generate chemokines and cytokines that contribute to the initiation and regulation of the inflammatory response during wound healing. While cross-talk between skin gamma-delta T-cells and keratinocytes contributes to the maintenance of normal skin and wound healing, mice lacking or defective in skin gamma-delta T-cells show a delay in wound closure and a decrease in the proliferation of keratinocytes at the wound site.

The proliferative phase generally follows and overlaps with the inflammatory phase, and is characterized by epithelial proliferation and migration over the provisional matrix within the wound (re-epithelialization). In the reparative dermis, fibroblasts and endothelial cells are the most prominent cell types present and support capillary growth, collagen formation, and the formation of granulation tissue at the site of injury. Within the wound bed, fibroblasts produce collagen as well as glycosaminoglycans and proteoglycans, which are major components of the extracellular matrix (ECM). Following robust proliferation and ECM synthesis, wound healing enters the final remodeling phase, which can last for years. In this phase, regression of many of the newly formed capillaries occurs, so that vascular density of the wound returns to normal. One critical feature of the remodeling phase is ECM remodeling to an architecture that approaches that of the normal tissue. The wound also undergoes physical contraction throughout the entire wound-healing process, which is believed to be mediated by contractile fibroblasts (myofibroblasts) that appear in the wound.

The role of stem cells (SC) in cutaneous wound healing and tissue regeneration is a topic of increasing research attention, with a focus on the role of adult stem cells such as epidermal stem cells and bone-marrow (BM)-derived cells (BMDCs). Epidermal stem cells reside in the bulge area of hair follicles and in the basal layer of the epidermis and give rise to the keratinocytes that migrate andre-epithelialize wounds. Normal skin is also a target organ for BMDCs. Two main stem cell populations are present in the bone marrow: hematopoietic SC (HSC) and mesenchymal SC (MSC). BM-MSCs are able to differentiate into a variety of cell types, including adipocytes, osteoblasts, chondrocytes, fibroblasts, and keratinocytes. Endothelial progenitor cells (EPCs) derived from the HSC lineage are key cells that contribute to neovascularization. Both BM-MSCs and EPCs are involved in the cutaneous wound-healing process. Wound-induced hypoxia triggers the mobilization of bone marrow EPCs to the circulation, playing a significant role in the process of neovascularization.

Several different cell types are involved in the woundhealing process, and, as described above, the cellular activities of any particular cell type may also vary during different stages of repair. The complexity and coordination of the healing process are major hurdles to therapeutic approaches, since any therapeutic must effectively be sequenced to the appropriate stage [6].

\section{Types of Wound Healing}

There are two main types of wound healing: primary healing and secondary healing. Most surgical wounds undergo primary closure in which there is minimal tissue loss and the 
wound edges can be satisfactorily approximated. This allows for primary healing in which there is rapid epithelialisation of the wound and minimal scarring [7].

Secondary healing refers to the process where a fullthickness wound is intentionally left open. This may be due to the presence of infection or an inability to satisfactorily approximate the wound edges. In secondary healing the wound heals by the natural way of granulation, eventual contraction and slow epithelialisation.4-6 Wounds that undergo secondary healing often result in larger scars $[8,9]$.

The following are the most common types of chronic wounds treated at our Wound Healing Program:
A. Venous Leg Ulcers
B. Diabetic Ulcers
C. Pressure Ulcers
D. Non-healing wounds of traumatic origin

Our program also features Hyperbaric Oxygen Therapy (HBOT), a non-invasive treatment that involves high levels of concentrated oxygen which accelerates cell growth to create healing while it enhances the body's natural healing capabilities and promotes more rapid chronic wound recovery.

The most common indications for Hyperbaric Oxygen Therapy, approved by most insurance companies for the treatment of non-healing wounds, include:
A. Diabetic wounds of the lower extremities
B. Chronic refractory osteomyelitis
C. Compromised skin grafts
D. Osteoradionecrosis
E. Late effects of radiation therapy
F. Crush injuries
G. Acute carbon monoxide intoxication
H. Gas Gangrene [10].

\section{Surgical Wound Care}

\section{Principles}

Regardless of the mechanism of wound healing, the aims of post-operative wound care remain the same: to allow the wound to heal rapidly without complications, and with the best functional and aesthetic results [11].

Wounds intended to be healed by primary healing should, in particular, have their wound edges well approximated. In the initial phases of healing, there is only minimal tensile strength in the wound as remodelling of the collagen fibres has not occurred. As such, additional support in the form of sutures, staples or tapes is required until full remodelling and epithelialisation occur.

\section{Dressing of the Surgical Wound \\ Definition of terms}

Clean versus sterile technique: Various definitions and descriptions of dressing technique for wound care exist. Terms have been used interchangeably and all are subject to individual interpretation. The following definitions provide a point of reference for the terms used in this document [12].

Sterile technique: Sterile is generally defined as meaning free from microorganisms [13] Sterile technique involves strategies used in patient care to reduce exposure to microorganisms and maintain objects and areas as free from microorganisms as possible. Sterile technique involves meticulous hand washing, use of a sterile field, use of sterile gloves for application of a sterile dressing, and use of sterile instruments. "Sterile to sterile" rules involve the use of only sterile instruments and materials in dressing change procedures; and avoiding contact between sterile instruments or materials and any non-sterile surface or products. Sterile technique is considered most appropriate in acute care hospital settings, for patients at high risk for infection, and for certain procedures such as sharp instrumental wound debridement [14-17].

Clean technique: Clean means free of dirt, marks, or stains. Clean technique involves strategies used in patient care to reduce the overall number of microorganisms or to prevent or reduce the risk of transmission of microorganisms from one person to another or from one place to another. Clean technique involves meticulous handwashing, maintaining a clean environment by preparing a clean field, using clean gloves and sterile instruments, and preventing direct contamination of materials and supplies. No "sterile to sterile" rules apply. This technique may also be referred to as non-sterile. Clean technique is considered most appropriate for long-term care, home care, and some clinic settings; for patients who are not at high risk for infection; and for patients receiving routine dressings for chronic wounds such as venous ulcers, or wounds healing by secondary intention with granulation tissue.

Aseptic technique: Asepsis or aseptic means free from pathogenic microorganisms. Aseptic technique is the purposeful prevention of the transfer of organisms from one person to another by keeping the microbe count to an irreducible minimum. Some authors have made a distinction between surgical asepsis or "sterile technique" used in surgery and medical asepsis or "clean technique" that involves procedures to reduce the number and transmission of pathogens.

No touch technique: No touch is a method of changing surface dressings without directly touching the wound or any surface that might come in contact with the wound. Clean gloves are used along with sterile solution/supplies/dressings that are maintained as clean [18]. 
Definition of infection: Infection has been defined as a continuum from contamination, colonization, critical colonization, biofilm, and infection.

Contamination: Contamination is the presence of nonreplicating microorganisms on the surface of the wound. All open wounds have some level of bacterial burden that is ordinarily cleared by the host [19].

Colonization: In colonization, microorganisms attach to the wound surface and replicate but do not impair healing or cause signs and/or symptoms of infection. The bacteria are not pathogenic and do not require treatment. All chronic wounds are colonized to varying degrees.

Critical colonization: With critical colonization, the organisms attach to the wound surface, replicate and multiply to a level that affects skin cell proliferation and tissue repair without provoking systemic signs of infection. There is no invasion of the healthy tissue at this point.

Biofilm: Approximately $70 \%$ of chronic wounds have biofilm. When organisms adhere to the wound surface, they begin to develop biofilm, which is a complex system of microorganisms embedded in an extracellular, polysaccharide matrix that protects from the invasion of other organisms, phagocytosis, and many commonly used antibiotics and antiseptics. Biofilms are difficult to treat and eradicate. Recently it has been proposed that biofilm might be present in all chronic wounds.

Infection: Infection occurs when organisms on the wound surface invade the healthy tissue, reproduce, overwhelm the host resistance, and create cellular injury leading to local or systemic symptoms [20-24] Infection is often described quantitatively as a bacterial count of greater than 1015 colony-forming units (CFU) per gram of tissue. However, some organisms such as beta-hemolytic streptococci impair wound healing at less than 1015 CFU per gram of tissue [25]. According to Kravitz [26] infection should be defined as the presence of bacteria in any quantity that impairs wound healing.

Clinical signs of infection include lack of healing after 2 weeks of proper topical therapy, erythema, increase in amount or change in character of exudate, odor, increased local warmth, friable granulation tissue, edema or induration, pain or tenderness, fever, chills, elevated white blood cell count, and elevated glucose in patients with diabetes. In patients who are immunosuppressed or have ischemic wounds, signs of infection can be subtle. Signs of inflammation such as a faint halo of erythema and moderate amounts of drainage might be the only signs of an infected arterial wound [12].Studies have shown that in chronic wounds, increasing pain, friable granulation tissue, wound breakdown, and foul odor have high validity for infection $[27,28]$.

\section{Complications of Surgical Wound}

Two common complications of surgical wounds are infections and wound dehiscence [29].

\section{Disordered wound healing}

Most wounds heal without complications and healing is not impaired in the elderly unless there are specific adverse factors or complications. Factors which may affect healing rate are [30]:

I. Poor blood supply.

II. Excess suture tension.

III. Long-term steroids.

IV. Immunosuppressive therapy.

V. Radiotherapy.

VI. Severe rheumatoid disease.

VII. Malnutrition and vitamin deficiency.

\section{Wound dehiscence}

I. This affects about $2 \%$ of midline laparotomy wounds.

II. It is a serious complication with a mortality of up to $30 \%$.

III. It is due to failure of wound closure technique.

IV. It usually occurs between 7 and 10 days postoperatively.

V. Often, it is heralded by serosanguinous discharge from the wound.

VI. It should be assumed that the defect involves the whole of the wound.

VII. Initial management includes opiate analgesia, sterile dressing to the wound, fluid resuscitation and early return to theatre for re-suture under general anaesthesia.

\section{Incisional Hernia [31]}

A. This occurs in $10-15 \%$ of abdominal wounds, usually appearing within the first year but can be delayed by up to 15 years after surgery.

B. Risk factors include obesity, distension and poor muscle tone, wound infection and multiple use of the same incision site.

C. It presents as a bulge in the abdominal wall close to a previous wound. It is usually asymptomatic but there may be pain, especially if strangulation occurs. It tends to enlarge over time and become a nuisance.

D. Management: surgical repair where there is pain, strangulation or nuisance. The use of laparoscopic techniques and biosynthetic mesh is being evaluated $[32,33]$.

\section{Conclusion}

The management of surgical wounds is very important part of post-operative recovery and the medicals and the wound care nurses should monitor the process of acute wound healing, prevent wound complications and treat appropriately if complications arise. They should care about the wound properly and prevent the wound from its complication which would lead into further complications. 


\section{References}

1. Yao K, Bae L, Yew WP (2013) Post-operative wound management. Aust Fam Physician 42(12): 867-870.

2. Abel J, Walter T, Carey LB, Rosenberg J, Noonan K, et al. (2013) Circles of care: should community development redefine the practice of palliative care? BMJ Support Palliat Care 3(4): 383-388.

3. Sibbald RG, Krasner DL, Lutz JB (2010) SCALE: skin changes at life's end: final consensus document: October 1, 2009. Adv Skin Wound Care 23(5): 225-236.

4. Alvarez OM, Meehan M, Ennis W, David RT, Frank D et al. (2002) Chronic wounds: palliative management for the frail population. Wounds 14(suppl 8): 13-18.

5. O'Brien T, Welsh J, Dunn FG (1998) ABC of palliative care: nonmalignant conditions. BMJ 316(7127): 286-289.

6. Guo S, DiPietro LA (2010) Factors Affecting Wound Healing. J Dent Res 89(3): 219-229

7. Velnar T, Bailey T, Smrkolj V (2009) The wound healing process: an overview of the cellular and molecular mechanisms. J Int Med Res 37(5): 1528-1542.

8. Rivera AE, Spencer JM (2007) Clinical aspects of full thickness wound healing. Clin Dermatol 25(1): 39-48.

9. Witte MB, Barbul A (1997) General principles of wound healing. Surg Clin North Am 77(3): 509-528.

10. Wound Healing Program at Winthrop-University Hospital, USA.

11. Singer AJ, Dagum AB (2008) Current management of acute cutaneous wounds. N Engl J Med 359(10): 1037-1046.

12. Journal of Wound, Ostomy\& Continence Nursing.

13. Rowley S, Clare S, Macqueen S, Molyneux R (2010) ANTT v2: an updated practice framework for aseptic technique. Br J Nurs 19(5): S5-S11.

14. Bates-Jensen BM, Ovington LG (2007) Management of exudate and infection. In: Sussman C, Bates-Jensen B (Eds.), Wound Care: A Collaborative Practice Manual for Physical Therapists and Nurses. $\left(3^{\text {rd }}\right.$ edn), p. 215.

15. Ferreira AM, De Andrade D (2008) Integrative review of the clean and sterile technique, agreement and disagreement in the execution of dressing. Acta Palulista de Enfermagem 21(1): 117-121.

16. Aziz AM (2009) Variations in aseptic technique and implications for infection control. Br J Nurs 18(1): 26-31.

17. Pegram A, Bloomfield J (2010) Wound care: principles of aseptic technique. Ment Health Pract 14(2): 14-18.

This work is licensed under Creative

Commons Attribution 4.0 License
18. Rolstad BS, Bryant RA, Nix DP (2012) Topical management. In: Bryant R, Nix D (Eds.), Acute \& Chronic Wounds: Current management Concepts. ( $4^{\text {th }}$ edn), pp. 289.

19. Stotts NA (2012) Wound Infection: Diagnosis and Management. In: Bryant R, Nix D (Eds.), Acute \& Chronic Wounds: Current Management Concepts. ( $4^{\text {th }}$ edn), pp. $270-278$.

20. Sibbald RG, Woo KY, Ayello EA (2009) Infection and inflammation Ostomy Wound Manag 55(1): 15-18.

21. Landis SJ (2008) Chronic wound infection and antimicrobial use. Adv Skin Wound Care 21(11): 531-540.

22. Cowan T (2010) Biofilms and their management: implications for the future of wound care. J Wound Care 19(3): 117-120.

23. Wolcott RD, Cox SB, Dowd SE (2010) Healing and healing rates of chronic wounds in the age of molecular pathogen diagnostics. J Wound Care 19(7): 272-281.

24.Gray M, Doughty D (2001) Clean versus sterile technique when changing wound dressings. J Wound Ostomy Contin Nurs 28(3): 125128.

25. Bowler PG (2003) The $10^{5}$ bacterial growth guideline: reassessing its clinical relevance in wound healing. Ostomy Wound Manage 49(1): 4453.

26. Kravitz S (2006) Infection: are we defining it accurately? Adv Skin Wound Care 19(4): 176

27. Cutting KF, White RJ (2005) Criteria for identifying wound infectionsRevisited. Ostomy Wound Manage 51(1): 28-34.

28. Gardner SE, Frantz RA, Doebbling BN (2001) The validity of the clinical signs and symptoms used to identify localized chronic wound infection. Wound Repair Regen 9(3): 178-186.

29. ColinTidy, Common Postoperative Complications

30. Guo S, Dipietro LA (2010) Factors affecting wound healing. J Dent Res 89(3): 219-229.

31. Kingsnorth A (2006) The management of incisional hernia. Ann R CollSurg Engl 88(3): 252-260

32. Garcea G, Ngu W, Neal CP, Robertson GS (2012) Results from a consecutive series of laparoscopic incisional and ventral hernia repairs. Surg Laparosc Endosc Percutan Tech 22(2): 131-135.

33.Bellows CF, Smith A, Malsbury J, Helton WS (2013) Repair of incisional hernias with biological prosthesis: a systematic review of current evidence. Am J Surg 205(1): 85-101.

Your next submission with Juniper Publishers will reach you the below assets

- Quality Editorial service

- Swift Peer Review

- Reprints availability

- E-prints Service

- Manuscript Podcast for convenient understanding

- Global attainment for your research

- Manuscript accessibility in different formats

( Pdf, E-pub, Full Text, Audio)

- Unceasing customer service

Track the below URL for one-step submission https://juniperpublishers.com/online-submission.php 